\title{
Effect of Air-Oxygen and Argon-Oxygen Mixtures on Dielectric Barrier Discharge Decomposition of Toluene
}

\author{
O. Godoy-Cabrera ${ }^{a, b}$, R. López-Callejas ${ }^{a, b}$, R. Valencia ${ }^{a}$, A. Muñoz-Castro ${ }^{a}$, S. R. Barocio ${ }^{a}$, \\ E. Chávez A ${ }^{a}$, A. Mercado-Cabrera ${ }^{a}$, A. de la Piedad-Beneitez ${ }^{b}$, \\ B. Rodríguez-Méndez ${ }^{c}$, and J. Rodríguez-Arce ${ }^{c}$ \\ ${ }^{a}$ Instituto Nacional de Investigaciones Nucleares, Plasma Physics Laboratory, \\ Apartado Postal No.18-1027 Col. Escandón C. P. 11801, México D.F., Mexico \\ ${ }^{b}$ Instituto Tecnológico de Toluca, Electronics Department, \\ Apartado Postal 890, Toluca, Mexico \\ ${ }^{c}$ Instituto Tecnológico y de Estudios Superiores de Monterrey, Campus Toluca, \\ Av. Eduardo Monroy Cárdenas 2000, Toluca, Edo. de México, C.P. 50252, Mexico
}

Received on 4 February, 2004; revised version received on 20 May, 2004

\begin{abstract}
One alternative application in the decomposition and destruction of volatile organic compounds (VOCs) by a silent plasma dielectric barrier discharge (DBD) has been successfully accomplished. For this purpose, we have designed and constructed two pairs of cells, of rectangular and circular geometries, $333.96 \mathrm{~cm}^{3}$ each cell, and a similar second pair of $62.25 \mathrm{~cm}^{3}$ each one. Resonant inverters for low $(3.3 \mathrm{kHz})$ and high $(100 \mathrm{kHz})$ frequencies were also designed and applied to these cells. The specification of the main physical parameters of each cell contemplates: $i$ ) a first order degradation ratio of the compound, and $i i$ ) air breakdown at atmospheric pressure as a function of the carrying gas. The power consumed by the cells during the discharges was computed both theoretically and experimentally by Manley's method. The equipment was applied to the degradation of toluene, which has been degraded by an oxidation process in air-oxygen and argon-oxygen gas mixtures at atmospheric pressure within the cells. The destruction efficiency was measured as a function of the initial concentration. When air is used as an oxidant, a clear formation of solid products on the walls of dielectric glass plates has been observed, such deposits being polymeric in nature. These deposits seem to be responsible for a decline in the degradation efficiency of the treated compounds.
\end{abstract}

\section{Introduction}

Emission control of dilute toxic volatile organic compounds (VOC's) such as toluene $\left(\mathrm{C}_{6} \mathrm{H}_{5} \mathrm{CH}_{3}\right)$, oxylene $\mathrm{C}_{6} \mathrm{H}_{4}\left(\mathrm{CH}_{3}\right)_{2}$, trichloroetane $\left(\mathrm{C}_{2} \mathrm{H}_{3} \mathrm{CH}_{3}\right)$ and others, generated by several human activities, is one of the most important and urgent matters for environmental protection. In this sense, various technologies have been investigated and developed for the decomposition the VOC's. In particular, nonthermal plasma technologies (electrical discharge processing) have demonstrated their effectiveness in destroying VOC's [1-3].

Nonthermal or silent discharge plasmas (SDP) can be created in a dielectric barrier discharge cell (DBDC). The cell is excited by a high voltage sinusoidal signal, which produces a series of micro-discharges. When this voltage exceeds the breakdown value of the carrier gas, a current channel of a short lifetime, in the order of a few nanoseconds, is created. In DBDC, the energetic electrons are effective in dissociating molecular oxygen into ground state atomic oxygen, which is very effective in the initial attack on organic molecules. The product of an initial attack can be more reactive than the starting material. However, with sufficient energy deposition, the carbon in organic species leaves the cell as $\mathrm{CO}$ and $\mathrm{CO}_{2}$ while the hydrogen leaves as $\mathrm{H}_{2} \mathrm{O}$ [4].

We are engaged in a project to develop the DBDC process as a prototype demonstration of an effective means of destroying hazardous organic and polychlorinated compounds. In this paper we present the first results obtained from the degradation of toluene by the a two stage degradation system.

\section{Experimental Set-Up}

The degradation system is formed by a first stage consisting in a Thermal Treatment Reactor (TTR), and a second stage which is a silent plasma discharge (SPD) formed by DBDC (see Fig. 1). The hazardous toluene organic compound is mixed with a carrying liquid (in this case, demineralized light oil Mobil DTE 24 or DTE for short) at a predetermined flow. Toluene and DTE are combined with the oxidizing gas through an injector which atomizes the mixture (air with a 15 $1 / \mathrm{min}$ flow). This mixture is introduced into a packed bed column and heated up by a high temperature electric furnace. The temperature can be controlled up to $1000{ }^{\circ} \mathrm{C}$, thus conditioning the organic compound into a gaseous form. 


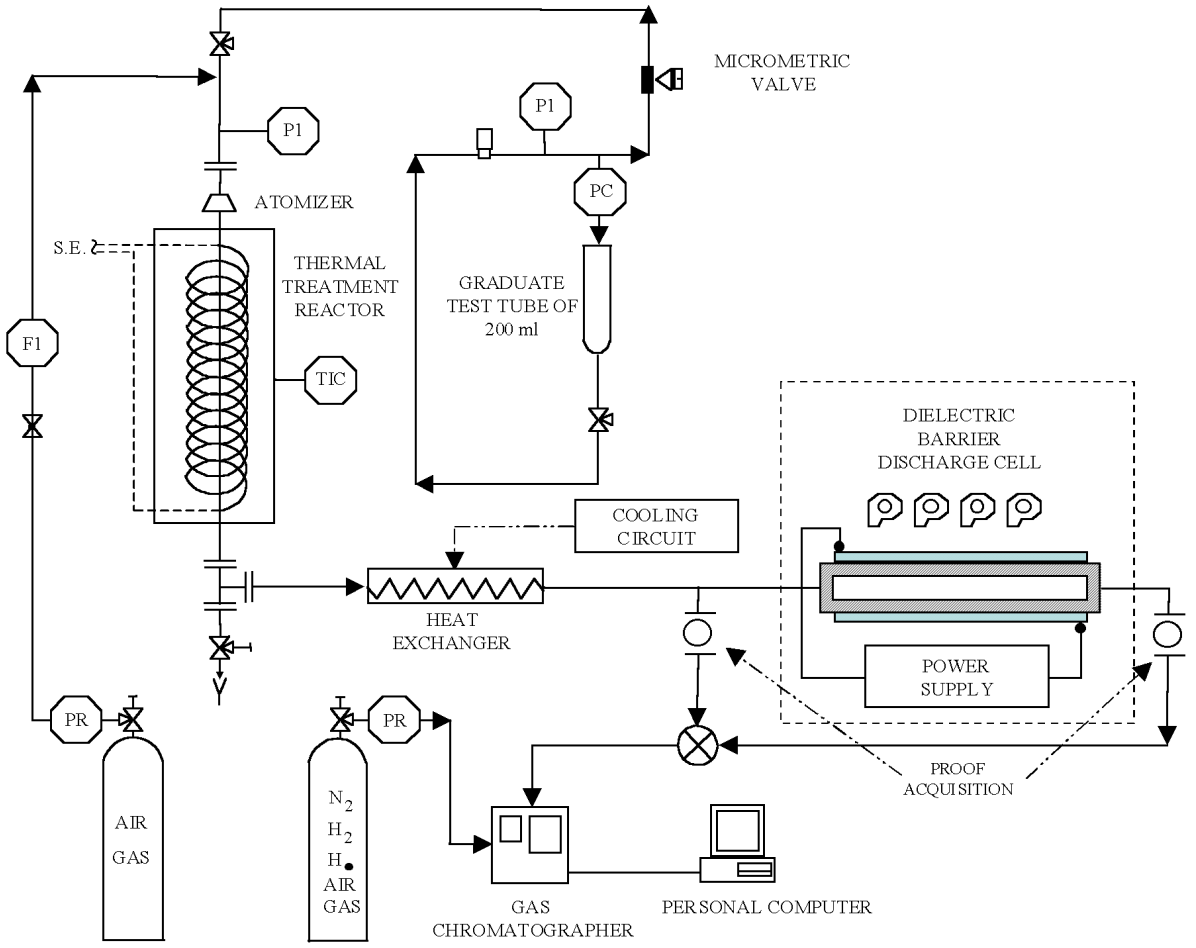

Figure 1. General scheme of the system for the degradation.

The gaseous mixture passes through a cylindrical container made of a Hastallowed and Hayes type stainless steel. The container presents a $7.6 \mathrm{~cm}$ diameter and a $152.4 \mathrm{~cm}$ length. In it, alumina is used as packing material. In this column the atomized hydrocarbons are converted into simpler chemical components by means of thermal combustion. The ensemble formed by the packed column and the electrical furnace has been called Thermal Treatment Reactor (TTR), and delivers a $1.5 \mathrm{~kW}$ average power. Five K-type thermocouples are used to measure the temperature at divers points within the column.

A heat exchanger (HX) is located at the output of the TTR. The function of the HX is to cool the gaseous compound down to room temperature. The HX consists of two stainless steel tubes, one inside the other. The gaseous compound flows inside the internal tube $(\phi=0.127 \mathrm{~m})$ whereas the external tube carries water in a counter flow. The cooling circuit includes a radiator, a pump, and a flow meter. The water flow can be controlled within the range $0-101 / \mathrm{min}$.

Thus, for instance, the approximate dimensions of one rectangular cell are $78.58 \mathrm{~cm}$ in length and $17.00 \mathrm{~cm}$ in width with a $0.25 \mathrm{~cm}$ gap, providing a main discharge area of $1335.86 \mathrm{~cm}^{2}$ and an active discharge volume of 333.96 $\mathrm{cm}^{3}$. Fig. 2 illustrates this planar cell. The cold plasma in the DBDC is produced by transient microdischarges (current streamers) when a high voltage high frequency sinusoidal signal, generated by a power series inverter, is applied to the DBDC. The typical power delivered by the inverter is $1.5 \mathrm{~kW}$ at $3.3 \mathrm{kHz}$ [5]. Finally, the pollutant residence time in the plasma can be estimated as the ratio of the cell volume to the gas mixture flow rate so that, in our case, the residence time turns out to be 1.33 seconds.

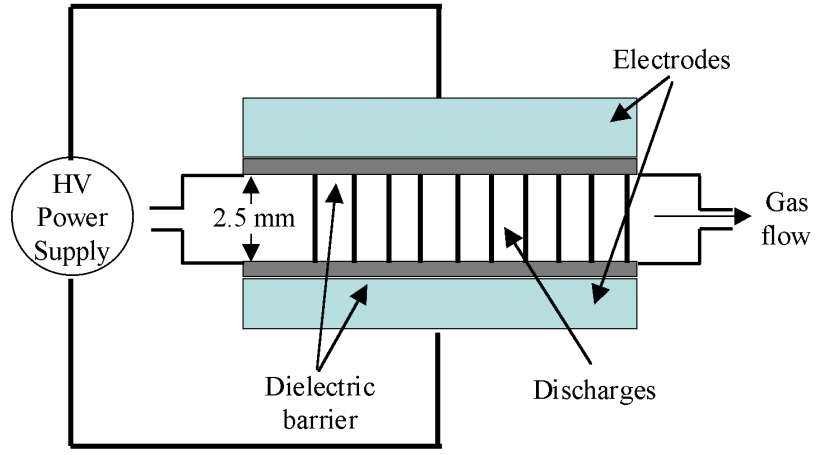

Figure 2. The dielectric barrier discharge cell.

\section{Results}

The experimental toluene degrading process was carried out on air-oxygen mixtures (21\%-79\% respectively) and argonoxygen mixtures $(20 \%-80 \%$ respectively). As a first step, the oxidation process at the end of the first stage was tested at room temperature by means of a combustion analyzer Madur Sensonic 2000. The results are presented in Table 1. It can be observed that the most effective oxidation process takes place with the $\mathrm{Ar}-\mathrm{O}_{2}$ mixture. This fact can be attributed to the lack of nitrogen in the mixture which reduces the formation of nitrogen oxides. 
TABLE 1: Oxidation process with air as a gas carrier

\begin{tabular}{|c|c|c|}
\hline Compound & Air/ $\mathrm{O}_{2}$ & Mixture $\mathrm{Ar} / \mathrm{O}_{2}$ \\
\hline $\mathrm{O}_{2}$ & $2 \%$ & $3.7 \%$ \\
\hline $\mathrm{CO}$ & $2349 \mathrm{ppm}$ & $86 \mathrm{ppm}$ \\
\hline $\mathrm{CO} \mathrm{O}_{2}$ & $15.3 \%$ & $12.6 \%$ \\
\hline $\mathrm{NO}$ & $252 \mathrm{ppm}$ & $8 \mathrm{ppm}$ \\
\hline $\mathrm{NO}_{2}$ & $114 \mathrm{ppm}$ & $0 \mathrm{ppm}$ \\
\hline $\mathrm{NO}_{\mathrm{X}}$ & $366 \mathrm{ppm}$ & $8 \mathrm{ppm}$ \\
\hline $\mathrm{SO}_{2}$ & $116 \mathrm{ppm}$ & $85 \mathrm{ppm}$ \\
\hline
\end{tabular}

The results from the power supplies are shown in Fig. 3. The voltage (top trace) and current (bottom trace) waveforms in the DBDC are seen in Fig. 3(a). The current trace shows i) the start and the end, and ii) the intermittent nature, of the silent discharges. The discharge start up coincides with $V_{i g} \sim 6250$ Volts, whereas its extinction occurs at the top voltage (in this case at $12.5 \mathrm{kV}$ of a possible maximum of $25 \mathrm{kV}$ ). The frequency of operation is $3.3 \mathrm{kHz}$. The Lissajous figure shown in Fig. 3(b) corresponds to the discharge in Fig. 3(a). The former one also shows the beginning and extinction of the discharge. The Lissajous figure is used to determine, experimentally, the power in the cell. First, the energy density is obtained with the formula

$$
E_{C}=\left(C_{m} V_{1}\right) V_{2}
$$

where $C_{m}$ is the measurement capacitance ( $2 \mu \mathrm{F}$ in the experiment) and $V_{1}$ is the ordinate voltage per division ( $1 \mathrm{~V} / \mathrm{div}$ in Fig. 3(b)). $V_{2}$ is the abscissa voltage per division $(5 \mathrm{kV} / \mathrm{div}$ in Fig. 3(b)), and corresponds to the attenuation factor of the high voltage probe. After substituting these values in Equation (1), the result $E_{C}=10 \mathrm{~mJ} / \mathrm{div}^{2}$ is obtained, which represents the energy in an area of one square of the oscilloscope grid.

The electron discharge total energy is proportional to the area of the parallelepiped $\left(A_{p}\right)$ (Fig. 3(b)). Thus

$$
A_{p}=d_{m} d_{M}
$$

where $d_{m}$ is the minor diagonal, and $d_{M}$ is the major diagonal of the parallelepiped. From Fig. 3(b) we have $d_{m}=1.8$ div and $d_{M}=2.7 \mathrm{div}$, therefore obtaining $A_{p}=4.86 \mathrm{div}^{2}$. The total energy is obtained using:

$$
W=E_{C} A_{p}
$$

which yields the result $W=48.6 \mathrm{~mJ}$.

The power consumed in the cell can be estimated by means of Manley's equation [6]:

$$
P=4 V_{i g} C_{d i e} f\left[V_{\text {peak }}-\left(\frac{C_{\text {die }}-C_{\text {gas }}}{C_{\text {die }}}\right) V_{i g}\right]
$$

where $V_{i g}$ and $V_{\text {peak }}$ are the ignition and extinction voltage respectively, $C_{d i e}$ and $C_{g a s}$ are the dielectric capacities of dielectric and gas respectively, and $f$ is the frequency of the high voltage signal. Hence, the resulting power value is $P=173.5 \mathrm{~W}$.
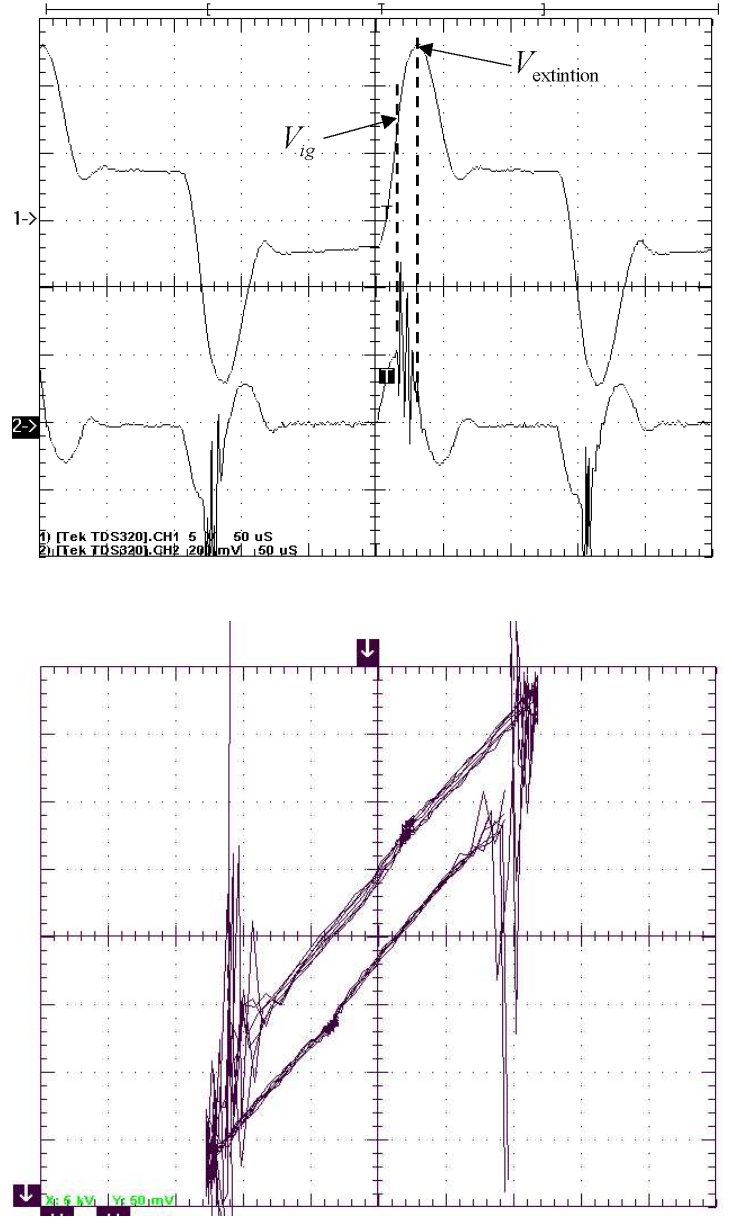

Figure 3. Waveforms obtained in the cell of volume $333.96 \mathrm{~cm}^{3}$ : (a) Voltage and current, (b) Lissajous figure.

The efficiency of the toluene degradation process was tested in the two stages through gas chromatography (GC) by means of a Varian 3400-CX equipment. The first test, on a 3\% toluene-DTE mixture, did not produce any chromatogrammes in any of both stages.

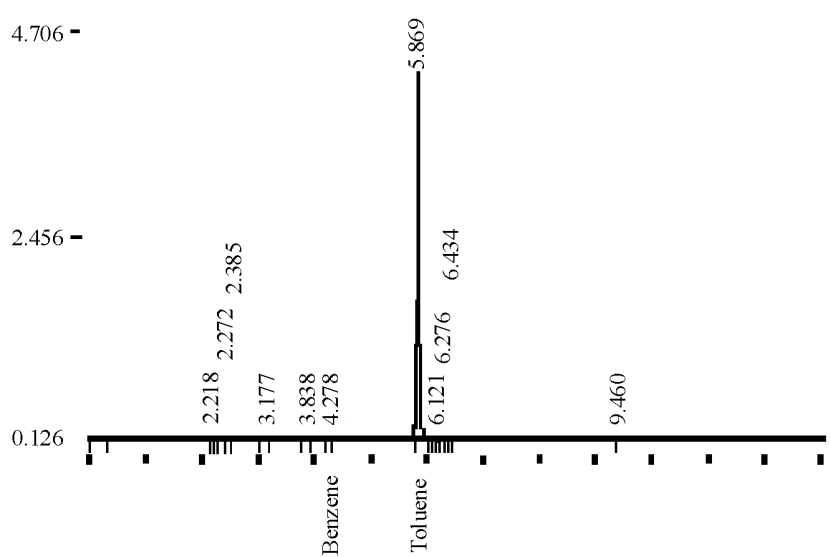

Figure 4. Chromatogramme of DTE + Toluene gaseous phase. 


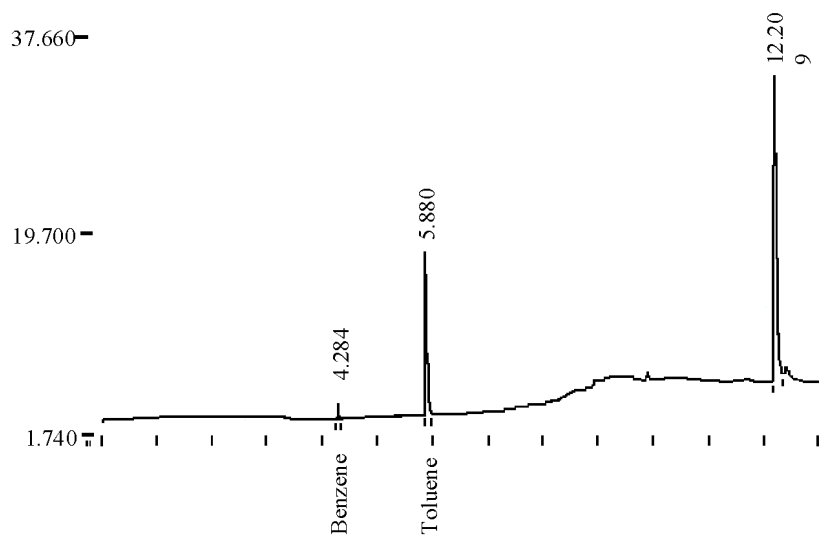

Figure 5. Chromatogramme of PFDTE + Toluene at first stage.

On the other hand, Fig. 4 exhibits the chromatogramme taken from toluene-DTE vapour at a $6 \%$ concentration. The information being shown corresponds to a $99.8811 \%$ concentration in volume, equivalent to 713285 chromatograph counts. The chromatogrammme in Fig. 5 corresponds to the first stage of the degradation process developed with an airoxygen carrier gas at a $34.2773 \%$ of the volume. The count number was 3066 so that the degradation at this stage reached $99.5701 \%$. In the case of Fig. 6, taken at the second degradation stage, a $2.8891 \%$ of the volume and 418 counts indicate a $86.366 \%$ degradation. Therefore, the total degradation, in both stages, amounts to a $99.9413 \%$.

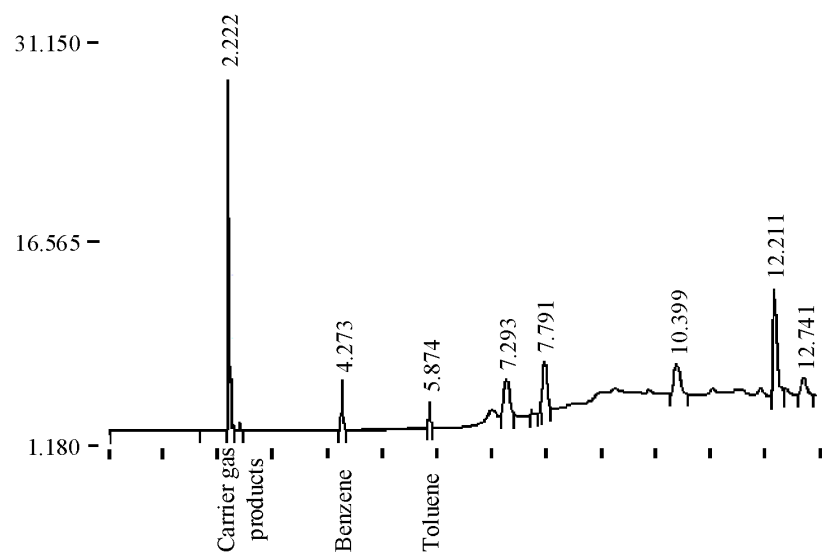

Figure 6. Chromatogramme of PFDTE + Toluene at the second stage.

Keeping the same $6 \%$ toluene concentration in DTE and admitting an $\mathrm{Ar}-\mathrm{O}_{2}(80 / 20)$ mixture as a carrier gas, no toluene peaks were obtained. This points to a very high degradation, rate, beyond the detection threshold of the chromatograph.

Given a 7.8 gr mass of toluene which is degraded in 40 minutes, this having a reported $173.5 \mathrm{~W}$ power supplied to the plasma in the DBDC, then the energy efficacy of our VOC decomposition can be estimated by the figure of merit $\gamma=14.80 \mathrm{~kW}-\mathrm{h} / \mathrm{kg}$.

During the silent barrier process with an air-oxygen mixture carrier, the glass wall insides of the cell became covered with a thin polymer film, possibly due to several competing chemical processes taking place simultaneously in the cell. Such polymer film deposits (see Fig. 7) usually result from the radical attack of oxygen on the toluene. In turn, the products of the partial oxidation are incorporated into the polymer, as it grows. In either case the result is a complex polymer comprising large amounts of oxygen. This is precisely observed in the infrared spectrum of Fig. 8 where strong bands at 701.8, 1043, 1208, 1457 and $1664.5 \mathrm{~cm}^{-1}$ can be noticed. These particular bands suggest that the polymer has incorporated large amounts of $O H$ and $C=O$ groups, respectively. With argon-oxygen as the chosen carrier, polymerization is practically null, as expected from the low concentrations of toluene in the DTE being employed.

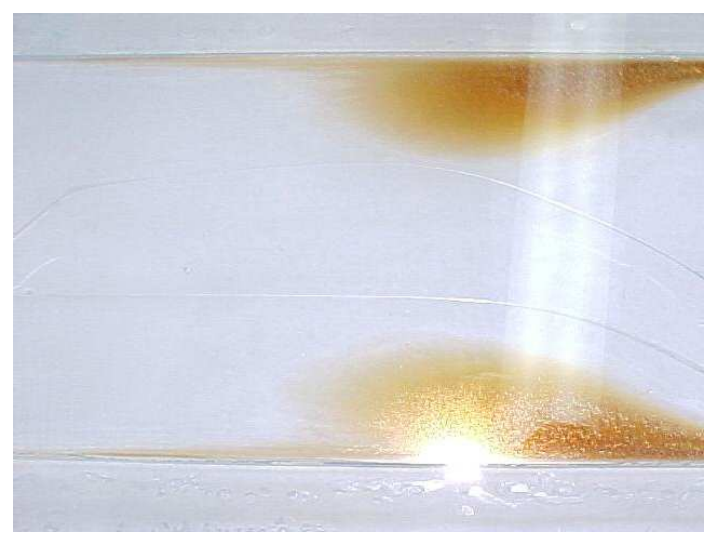

Figure 7. Deposition of polymer film on surfaces of DBDC.

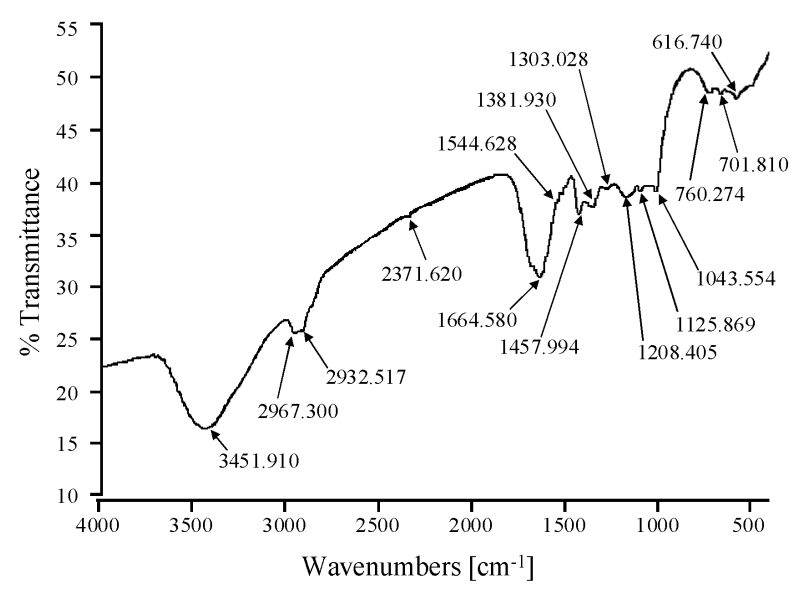

Figure 8. Infrared spectrum of polymer film depositions in the DBDC.

\section{Conclusions}

Through the testing and evaluation of a two stage packed bed DBDC, we have shown its effectiveness in degrading an organic compound such as toluene. For this purpose, two pairs of cells of different geometry, along with some specific resonant inverters, were designed and built, enabling the performance of the process in two distinct sequential regimes. 
In the case of an air-oxygen mixture $(21 \% / 79 \%)$, the degradation of toluene remained in the order of $99.94 \%$; while, with an argon-oxygen one $(80 \% / 20 \%)$, the degradation reached $99.9999 \%$. We have observed that the efficacy of the degradation processes conducted in air-oxygen mixtures became compromised by the formation of polymer films on the cell walls.

\section{Acknowledgements}

This work was performed with financial support from CONACYT under contract 39676-Y and COSNET under contracts 641.03-P and 642.02-03-PR. The authors wish to thank technical collaborators M. T. Torres M., M. A. Durán G. and I. Contreras V. for their contribution to the development of the project.

\section{References}

[1] D. Evans, L. A. Rosocha, G. K. Anderson, J. J. Coogan, and M. J. Kushner, J. Appl. Phys. 74-9, 5378 (1993).

[2] H. Kohno, A. A. Berezin, J. Chang, M. Tamura, T. Yamamoto, A. Shibuya, and S. Honda, IEEE Trans. on Ind. Applicat. 34-52, 953 (1998).

[3] T. Oda, T. Takahashi, and K. Tada, IEEE Trans. on Ind. Applicat., 35-2, 373 (1999).

[4] G. K. Anderson, H. Snyder, and J. Coogan, Plasma Chemical and Plasma Processing, 19-1, 131 (1999).

[5] O. Godoy-Cabrera, J. S. Benitez Read, R. Lopez-Callejas, and J. Pacheco-Sotelo, Int. J. Electronics, 87-3, 361 (2000).

[6] T. C. Manley, Trans. Electrochem. Soc. 84, 83 (1943). 